\title{
Increased expression of kisspeptin and GnRH forms in the brain of scombroid fish during final ovarian maturation and ovulation
}

\author{
Sethu Selvaraj ${ }^{1}$, Hajime Kitano ${ }^{1}$, Masafumi Amano², Hirofumi Ohga ${ }^{1}$, Michio Yoneda $^{3}$, Akihiko Yamaguchi ${ }^{1}$, \\ Akio Shimizu $^{3}$ and Michiya Matsuyama ${ }^{1 *}$
}

\begin{abstract}
Background: Kisspeptins (Kiss) are prime players in the control of reproductive function through their regulation of gonadotropin-releasing hormone ( $\mathrm{GnRH})$ expression in the brain. The experimental scombroid fish, chub mackerel (Scomber japonicus) expresses two kiss (kiss1 and kiss2) and three gnrh (gnrh1, gnrh2, and gnrh3) forms in the brain. In the present study, we analyzed expression changes of kiss and gnrh mRNAs in the brain and corresponding $\mathrm{GnRH}$ peptides in the brain and pituitary during final ovarian maturation (FOM) and ovulation.

Methods: Female fish possessing late vitellogenic oocytes were injected with GnRH analogue to induce FOM and ovulation. Fish were observed for daily spawning activities and sampled one week post-injection at germinal vesicle migration (GVM), oocyte hydration, ovulation, and post-ovulatory time periods. Changes in relative mRNA levels of kiss and gnrh forms in the brain were determined using quantitative real-time PCR. Changes in GnRH peptides in the brain and pituitary were analyzed using time-resolved fluoroimmunoassay.

Results: Both kiss 1 and kiss2 mRNA levels in the brain were low at late vitellogenic stage and increased significantly during the GVM period. However, kiss1 mRNA levels decreased during oocyte hydration before increasing again at ovulatory and post-ovulatory periods. In contrast, kiss 2 mRNA levels decreased at ovulatory and post-ovulatory periods. Levels of gnrh 1 mRNA in the brain increased only during post-ovulatory period. However, levels of gnrh2 and gnrh3 mRNAs were elevated during GVM and then, decreased during oocyte hydration before increasing again at ovulatory period. During post-ovulatory period, both gnrh2 and gnrh3 mRNA levels declined. Peptide levels of all three GnRH forms in the brain were elevated during GVM and oocyte hydration; their levels were significantly lower during late vitellogenic, ovulatory, and post-ovulatory periods. In contrast, pituitary GnRH peptide levels did not show any significant fluctuations, with the $\mathrm{GnRH} 1$ peptide levels being many-fold higher than the $\mathrm{GnRH} 2$ and GnRH3 forms.
\end{abstract}

Conclusion: The results indicate increased expression of multiple Kiss and GnRH forms in the brain and suggest their possible involvement in the regulation of FOM and ovulation in captive female chub mackerel.

Keywords: Kisspeptins, Kiss, GnRH, Mackerel, Brain, Pituitary, Spawning cycle

\footnotetext{
* Correspondence: rinya_m@agr.kyushu-u.ac.jp

'Laboratory of Marine Biology, Kyushu University, Fukuoka 812-8581, Japan

Full list of author information is available at the end of the article
} 


\section{Background}

In vertebrates, including teleosts, reproductive processes are regulated by the precise coordination of neuroendocrine hormones acting through the brain-pituitary-gonad (BPG) axis. A neurohormone, gonadotropin-releasing hormone $(\mathrm{GnRH})$, plays a central role by stimulating the synthesis and release of the pituitary gonadotropins (GtHs). These pituitary GtHs, follicle-stimulating hormone (FSH) and luteinizing hormone (LH), act on the gonads to stimulate steroidogenesis, which is responsible for progression of ovarian growth and maturation [1,2]. However, in recent years, kisspeptins, a member of the RF-amide family, have been shown to act as an upstream endogenous regulator of GnRH neurons in mammals [3,4]. Recent studies indicate that their role in teleostean fish is also conserved [5,6]. Kisspeptins primarily act at the level of GnRH neurons, which express kisspeptin receptor (GPR54 or Kiss1r) [7,8].

Studies in teleosts have revealed the presence of multiple kisspeptin forms (Kiss1, Kiss2) in the brain [6]. Moreover, teleosts brain expresses multiple GnRH forms (GnRH1, GnRH2, and GnRH3) with one or two forms regulating pituitary function $[9,10]$. These multiplicities have complicated our understanding of their physiological roles in the gonadal growth and maturation in teleosts, especially in females as they exhibit different forms of reproductive dysfunctions when reared in captivity [11].

The experimental scombroid fish model, chub mackerel (Scomber japonicus), is a multiple batch-spawning pelagic fish. It is one of the most commercially important marine fish species in Japan. This species has been targeted for aquaculture in recent years owing to a sharp decline in the wild population, high consumer demand, use in the tuna fishing industry as bait, and high early growth potential [12]. In southwestern Japan, wild-caught fish are being used for aquaculture production in sea pens [13]. However, vitellogenic females fail to undergo final ovarian maturation (FOM) and ovulation in aquaculture conditions $[13,14]$. Therefore, characterization and understanding of neuroendocrine pathways acting via BPG axis is critical to clarify the reproductive dysfunction in female chub mackerel [15]. Our group already standardized a protocol based on sustained GnRH analogue delivery system to induce FOM and ovulation in outdoor tanks during natural spawning season (April-June) [16]. This system allows us to sample fish at different stages of FOM and ovulation.

The chub mackerel brain expresses kiss1 and kiss2. During the seasonal ovarian cycle, kiss 2 mRNA levels decrease during vitellogenic and ovarian regression stages [17]. Also, the presence of three GnRH forms, namely GnRH1, GnRH2, and GnRH3 (previously seabream $\mathrm{GnRH}$, chicken GnRH-II, and salmon GnRH forms, respectively [18]) in the brain were demonstrated previously $[19,20]$. An increase in the pituitary peptide levels of GnRH1 was observed during ovarian growth and regression stages [20], in agreement with our immunocytochemical observation of dense GnRH1immunoreactive (ir) fibers localized close to FSH- and LH-producing cells in the pituitary [19]. In female gilthead seabream (Sparus aurata), which also express three $\mathrm{GnRH}$ forms as that of chub mackerel, an increase in the levels of all three forms of GnRH-encoding mRNAs in the brain was reported during FOM [21]. In the present study, to clarify the possible involvement of kisspeptin and GnRH system in the regulation of FOM and ovulation, we analyzed the expression profiles of kiss and gnrh mRNAs in the brain as well as corresponding GnRH peptides in the pituitary of chub mackerel after initial administration of $\mathrm{GnRH}$ analogue.

\section{Methods}

Fish and tissue sampling

Adult chub mackerel (2-year-old) were caught from the wild using purse seine during autumn 2008 and reared for six months in sea pens at a fish farm in the Oita prefecture, Kyushu Island. During the following spawning season (April-June), fish were transferred to Fishery Research Laboratory of Kyushu University and moved into 3-ton outdoor concrete tanks circulated with running seawater. The fish were acclimated and reared under natural photoperiod and temperature. Our previous studies indicated that female chub mackerel fail to undergo FOM and ovulation spontaneously in this captive system [13,14]. An induced spawning protocol based on sustained release GnRH delivery system was adopted from previous study [16].

After 3 days of acclimation, fish were anaesthetized with 2-phenoxyethanol $(100 \mathrm{mg} / \mathrm{l})$ and females with late vitellogenic oocytes (600-650 $\mu \mathrm{m}$ in diameter) were selected by ovarian biopsy using a plastic catheter tube (2 $\mathrm{mm}$ internal diameter), as described previously $[13,16]$. Males oozing milt under gentle abdominal pressure were selected. After selection of required number of females and males, intramuscular injection with the GnRH agonist (D-Ala ${ }^{6}$, des-Gly $\left.{ }^{10}\right)$-LHRH ethylamide (Sigma-Aldrich, St. Louis, USA) at $400 \mu \mathrm{g} / \mathrm{kg}$ body weight were performed on April $30^{\text {th }}$, May $13^{\text {th }}$, May $21^{\text {st }}$, and May $22^{\text {nd }}, 2009$ to obtain different ovarian stages, namely germinal vesicle migration (GVM), oocyte hydration (HY), ovulation (OV), and post-ovulation (POV), respectively. The sampling times were 13.00, $16.00,20.00$, and $6.00 \mathrm{~h}$ of the day, respectively. In all cases, injections were performed at $11.00 \mathrm{~h}$. Sampling times were fixed based on our previous data on time course of FOM and ovulation in chub mackerel induced by GnRHa [16]. Fish sampling for the analysis was performed on day 8 , based on previous reports showing the 
decline in the plasma concentration of GnRH agonist on day 5 after intramuscular injection with the GnRH agonist suspended in coconut oil in Plaice, Pleuronectes platessa $[22,23]$. The first spawning was observed $34-36 \mathrm{~h}$ post-injection, and subsequent daily spawning occurred between 22.00 and $24.00 \mathrm{~h}$. In the following experimental system, daily spawning of chub mackerel is observed for 20-30 days during the spawning season, when the water temperature ranged between $18-23^{\circ} \mathrm{C}$ (Yoneda et al., unpublished observations). The late vitellogenic (LV) stage fish were sampled before the start of induced spawning experiment.

Fish used in the experiment were sacrificed in accordance with the guidelines for animal experiments proposed by the Faculty of Agriculture and Graduate Course at Kyushu University and according to the laws (No. 105) and notifications (No. 6) of the Japanese government. The fork length, body, and gonad weights of each individual were measured before tissue sampling. The brain and pituitary of each fish were removed following decapitation, snap-frozen in liquid nitrogen, and stored at $-80^{\circ} \mathrm{C}$ until further analysis. For ovarian histological evaluation, ovary midsections from individual fish were fixed in Bouin's solution. To analyze the changes in kiss and gnrh mRNA levels in the whole brain and GnRH peptides in the whole brain and pituitary, two experimental sets of fish samples were used (Table 1). The brain tissue from the first set was used for mRNA analysis, and the second set was used for GnRH peptide analysis. Male fish were excluded from the analysis.

\section{Ovarian histology}

After fixation, ovary samples from each fish were dehydrated in a series of ethanol solutions up to $100 \%$, embedded in paraffin, and sectioned at 5-7 $\mu \mathrm{m}$ using a Leica RM 2155 rotary microtome (Leica, Germany). Sections were stained with hematoxylin and counterstained with eosin. The stained tissues were subsequently observed under a light microscope. Chub mackerel show asynchronous ovarian development, and ovarian stages were thus classified based on the developmental stages of first clutch oocytes as (1) LV, (2) GVM, (3) HY, (4) OV, and (5) POV.

\section{Quantitative real-time PCR analysis of kiss and gnrh mRNAs in the brain}

Quantitative real-time PCR (qRT-PCR) analysis was performed on an Mx 3000P quantitative PCR system (Stratagene). Total brain RNA was extracted using ISOGEN (Nippon Gene, Japan), according to the manufacturer's protocol. One microgram of total RNA from each brain sample was digested with DNase I (Invitrogen) and used as template for reverse transcription (RT) reaction. The cDNA synthesis was performed using Superscript III Reverse Transcriptase (Invitrogen) in a $20 \mu \mathrm{l}$ reaction mixture containing $2.5 \mathrm{mM}$ dNTP mix, random primers (100 ng/ $\mu$ l; Takara Bio Inc., Japan), 5X First-Strand buffer, $0.1 \mathrm{M} \mathrm{DTT}$, and RNase H (2 units). Based on our previous report on full-length cDNA sequences $[17,20]$, gene specific primers for chub mackerel kiss1, kiss2 (GenBank accession number: GU731672 and GU731673), gnrh1, gnrh2, and gnrh3 (GenBank accession number: HQ108193, HQ108194, and HQ108195) were designed from the open reading frame region of each gene using GENETYX software (Table 2) and validated with RT-PCR and agarose gel electrophoresis. Amplification of the beta ( $\beta$ )-actin (GenBank accession number: GU731674) was used as the endogenous reference gene to correct for differences in reverse transcription efficiency and template quantity. The qRT-PCR was performed using the Brilliant II Fast SYBR Green QPCR Master Mix (Stratagene), following the manufacturer's protocol. The thermocycling conditions were set as $95^{\circ} \mathrm{C}$ for $5 \mathrm{~min}$ and 40 cycles of $95^{\circ} \mathrm{C}$ for $10 \mathrm{sec}$ and $60^{\circ} \mathrm{C}$ for $30 \mathrm{sec}$. Dissociation curve analysis was also included; one cycle of $95^{\circ} \mathrm{C}$ for $1 \mathrm{~min}, 55^{\circ} \mathrm{C}$ for $30 \mathrm{sec}$, and $95^{\circ} \mathrm{C}$ for $30 \mathrm{sec}$. All transcripts were quantified using a standard curve method [24] and a previously validated qRT-PCR for kiss, gnrh, and $\beta$-actin mRNAs $[17,20]$. The PCR reaction mixture

Table 1 Fork length, body weight, and gonadosomatic index of female chub mackerel analyzed in the study period

\begin{tabular}{lllllll}
\hline \multirow{2}{*}{ Analyses } & \multicolumn{1}{c}{ Parameters } & \multicolumn{4}{c}{ Ovarian stages } \\
\cline { 3 - 7 } & & \multicolumn{1}{c}{ LV } & GVM & HY & OV & POV \\
\hline Kiss/GnRH mRNAs & Fork length (cm) & $33.6 \pm 0.4$ & $34.7 \pm 0.7$ & $34.6 \pm 0.5$ & $33.0 \pm 0.4$ & $34.7 \pm 0.6$ \\
\hline & Body weight (g) & $523.6 \pm 24.1$ & $637.9 \pm 54.7$ & $692.3 \pm 38.1$ & $522.1 \pm 13.7$ & $591.5 \pm 26.0$ \\
\hline & GSI (\%) & $7.3 \pm 1.4$ & $7.7 \pm 1.6$ & $13.7 \pm 2.8$ & $7.0 \pm 0.8$ & $6.2 \pm 1.1$ \\
\hline GnRH peptides & Fork length (cm) & 6 & 6 & 5 & 6 & 6 \\
\hline & Body weight (g) & $521.9 \pm 24.1$ & $578.6 \pm 30.0$ & $659.9 \pm 44.0$ & $513.5 \pm 19.3$ & $694.7 \pm 94.4$ \\
\hline & GSI (\%) & $6.7 \pm 0.8$ & $4.5 \pm 0.66$ & $8.2 \pm 1.8$ & $6.9 \pm 1.2$ & $8.0 \pm 2.7$ \\
\hline & $\mathrm{n}$ & 6 & 5 & 4 & 6 & 4 \\
\hline
\end{tabular}

Values are expressed as the mean \pm SEM. LV, late vitellogenesis; GVM, germinal vesicle migration; HY, hydration; OV, ovulation; POV, post-ovulation; GSI, gonadosomatic index (GSI=gonad weight/body weight without gonads $x$ 100). 
Table 2 List of primers used for real-time PCR expression analysis of kiss and gnrh mRNAs

\begin{tabular}{ll}
\hline Primer name & Nucleotide sequences (5/-3/) \\
\hline Mac. Kiss1 RT Fw & CTACGACTCCTTGTTGCTTTG \\
\hline Mac. Kiss1 RT Rv & TGATCTTCACTGTAGTTGGTGG \\
\hline Mac. Kiss2 RT Fw & CTGAACAGAGGACACAAGGAAG \\
\hline Mac. Kiss2 RT Rv & CTCAGGCTGAAACAAAGGTTAG \\
\hline Mac. RT sbGnRH Fw & GCTGCTTCTTGGATCAGTAGTG \\
\hline Mac. RT sbGnRH Rv & AACCCCTCAACTACATCATCC \\
\hline Mac. RT cGnRH-II Fw & TGGGGTTGCTTCTATGTGTG \\
\hline Mac. RT cGnRH-II Rv & TCCTCTGAAATCTCTGGTGTG \\
\hline Mac. RT sGnRH Fw & ACTGGTCCTATGGATGGCTAC \\
\hline Mac. RT sGnRH Rv & TTCAGGAAGAGACACCACACC \\
\hline
\end{tabular}

$(20 \mu \mathrm{l})$ contained 1X Brilliant II Fast SYBR Green QPCR Master Mix, $0.1 \mu \mathrm{M}$ each of forward and reverse primer, and $1 \mu \mathrm{l} \mathrm{cDNA}$ sample. For negative control, cDNA sample was replaced with autoclaved distilled water. Duplicate reactions were performed for the standards, target and reference genes, from 5-6 fish collected per ovarian stage. The amounts of target and endogenous reference gene in experimental samples were determined from the respective standard curves using $\mathrm{MxPrO}$ QPCR Software. Transcript levels of kiss and gnrh mRNAs were normalized to the levels of $\beta$-actin; the data are expressed as relative mRNA levels. Based on two qRT-PCR assays, the intra- and interassay coefficients of variation (CV) for kiss and gnrh mRNAs were less than $8 \%$. All qRTPCR assays were conducted where practically possible according to the MIQE (Minimum Information for Publication of qRT-PCR experiments) guidelines by Bustin et al. [25].
Time-resolved fluoroimmunoassay analysis of GnRH peptides in the brain and pituitary

Brain and pituitary extracts were prepared following the protocol described earlier [26,27]. Brain and pituitary GnRH peptide levels were measured using a previously developed time-resolved fluoroimmunoassay (TR-FIA) system to quantify levels of GnRH1 (sbGnRH form), GnRH2 (cGnRH-II form), and GnRH3 (sGnRH form) in tissue extracts $[28,29]$. Parallelism between the typical standard curves of each GnRH peptide and the corresponding competition curves of sample extracts of chub mackerel was confirmed with serially two-fold-diluted standards and sample extracts in TR-FIA assay buffer [20]. The detection range, minimum detectable limit, and cross reactivity data are presented in our recent publication [20]. The intra- and interassay $\mathrm{CV}$ values of TR-FIA for GnRH1 were $9.0 \%$ and $19.6 \%$, those for GnRH 2 were $7.5 \%$ and $5.8 \%$, and those for GnRH3 were $7.4 \%$ and $10.3 \%$. GnRH peptide levels in the brain and pituitary samples are expressed as ng/mg tissue and ng/ pituitary, respectively.

\section{Data analysis}

All data are represented as the mean \pm standard error of the mean. Changes in the levels of kiss and gnrh mRNAs in the brain and GnRH peptides in the brain and pituitary during different ovarian stages were analyzed by one-way ANOVA, followed by Tukey's multiple comparison test. $\mathrm{p}<0.05$ was considered significant and different letters in figures represent significant differences between different ovarian stages. All analyses were conducted in GraphPad Prism4.

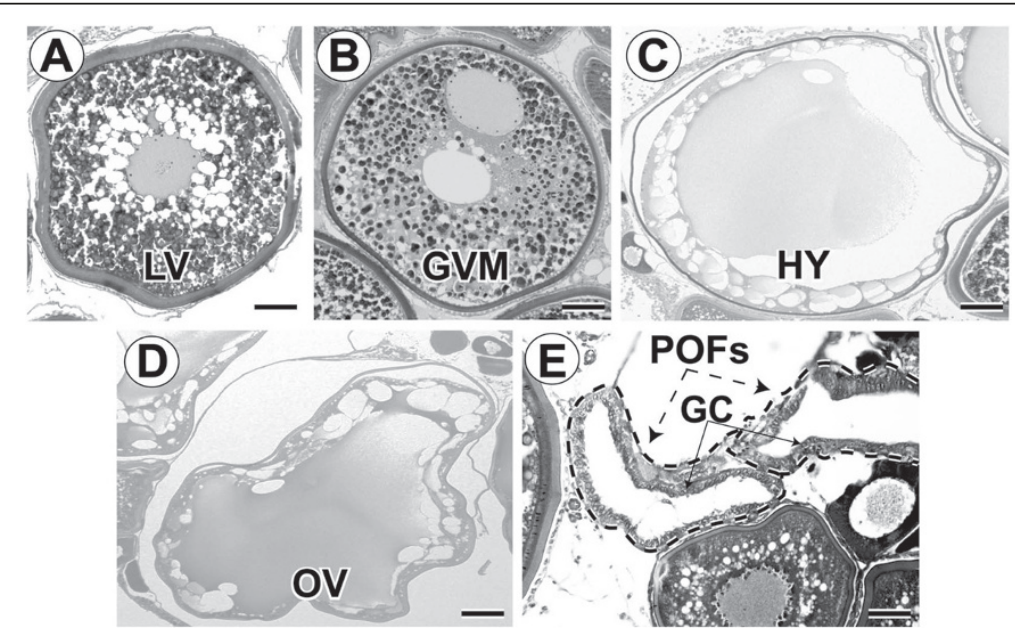

Figure 1 Histological images of ovarian stages of chub mackerel analyzed in the study period. (A) Late vitellogenesis (LV). (B) Germinal vesicle migration (GVM). (C) Hydration (HY). (D) Ovulation (OV). (E) Post-ovulation (POV); dashed lines indicate presence of post-ovulatory follicles (POFs) with hypertrophied granulosa cells (GC). Scale bars $=100 \mu \mathrm{m}$. 


\section{Results}

\section{Ovarian histology}

The histological images of different ovarian stages analyzed in the present study are presented in Figure 1. LV stage oocytes (Figure 1A) were characterized by the presence of yolk globules around centrally located germinal vesicle of first clutch late vitellogenic oocytes. In the GVM stage oocytes (Figure 1B), GV migration to the animal pole was observed with one or two continuous masses of yolk in the central region of the oocyte. HY stage oocytes (Figure 1C) were transparent and enlarged after germinal vesicle breakdown. OV stage (Figure 1D) was characterized by the presence of freshly ovulated eggs in the ovarian cavity. POV stage (Figure 1E) showed the presence of 6- to 8-h old post-ovulatory follicles (POFs) in the ovarian tissue, characterized by hypertrophied follicular granulosa cells [30].

\section{Changes in kiss 1 and kiss 2 mRNA levels in the brain}

The levels of kiss1 mRNA significantly increased from the LV stage to GVM $(\mathrm{P}<0.001)$; declined during $\mathrm{HY}$ and then increased during the OV and POV $(\mathrm{P}<0.001$ for $\mathrm{OV}$ and $\mathrm{P}<0.05$ for $\mathrm{POV}$ ) periods (Figure $2 \mathrm{~A}$ ). Similar to kiss1, kiss2 mRNA levels significantly increased during the GVM stage $(\mathrm{P}<0.001)$. However, kiss $2 \mathrm{mRNA}$ levels declined during the $\mathrm{OV}$ and $\mathrm{POV}$ periods $(\mathrm{P}<0.01$ for $\mathrm{OV}$ and $\mathrm{P}<0.001$ for POV; Figure $2 \mathrm{~B}$ ).

\section{Changes in gnrh1, gnrh2, and gnrh3 mRNA levels in the} brain

The levels of gnrh1 mRNA showed significant increase during the POV period $(\mathrm{P}<0.05$; Figure $3 \mathrm{~A})$. However, gnrh2 and gnrh3 mRNA levels significantly increased during the GVM period $(\mathrm{P}<0.001)$ and then decreased during HY period $(\mathrm{P}<0.001)$. Again, their levels increased during $\mathrm{OV}$ period and then decreased during POV period (Figure 3B, C).

\section{Changes in GnRH1, GnRH2, and GnRH3 peptide levels in the brain and pituitary}

GnRH1, GnRH2, and GnRH3 peptide levels in the brain were significantly elevated during the GVM $(\mathrm{P}<0.05)$ and HY $(\mathrm{P}<0.001)$ periods (Figure 4A, B, C). GnRH1 levels significantly declined during $\mathrm{OV}$ and POV periods $(\mathrm{P}<0.01$; Figure $4 \mathrm{~A})$; GnRH2 levels were low during $\mathrm{OV}$ and POV periods but did show any significant differences with HY levels (Figure 4B); GnRH3 levels significantly declined during $\mathrm{OV}(\mathrm{P}<0.05)$ and were low during POV periods (Figure $4 \mathrm{C}$ ).

Pituitary peptide levels of all three GnRH forms did not show any significant differences among different ovarian stages (See Additional file 1: Figure S1).

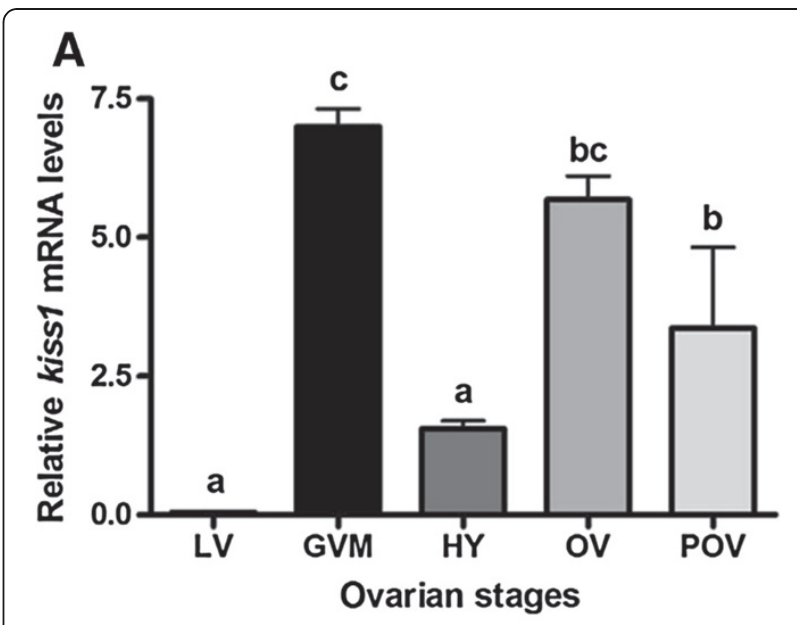

\section{B}

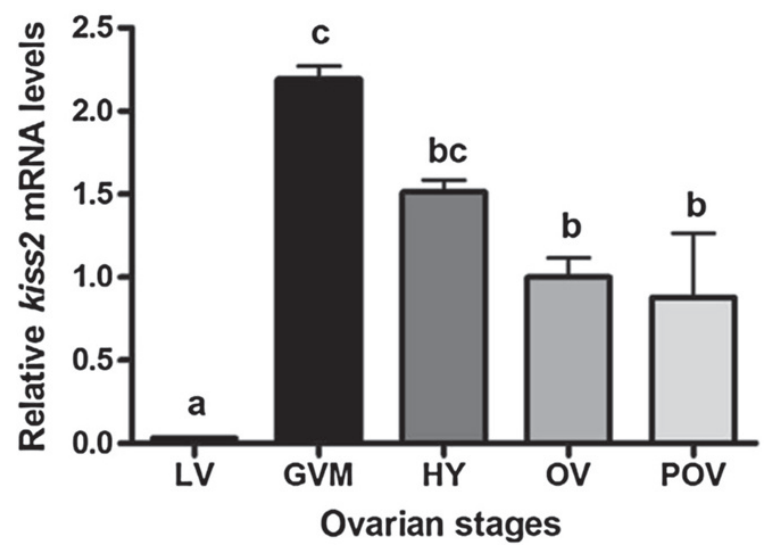

Figure 2 Changes in kiss 1 (A) and kiss2 (B) mRNA levels in the brain of adult chub mackerel during different stages of spawning cycle. Each bar represents mean \pm SEM from 5-6 fish per ovarian stage (Refer Table 1). Different letters above the bars represent significant differences $(p<0.05)$ between stages. LV, late vitellogenesis; GVM, germinal vesicle migration; HY, hydration; OV, ovulation; POV, post-ovulation.

\section{Discussion}

The present study is part of a series of works targeted towards understanding the molecular basis of chub mackerel reproduction with the aim of correcting reproductive dysfunction in captivity $[15,17,19,20,31]$. In the present study, after GnRHa administration to fish, first spawning was observed 34-36 $\mathrm{h}$ post-injection and subsequent daily spawning occurred between 22.00 and $24.00 \mathrm{~h}$ till day 7 post-injection. Based on the previous reports demonstrating significant decline in the plasma concentration of GnRH agonist on day 5 after intramuscular injection with the GnRH agonist suspended in coconut oil in the Plaice $[22,23]$, results of the present study likely indicate an endogenous profile of female chub mackerel undergoing FOM and ovulation in captivity.

It was interesting to find that both kiss 1 and kiss2 mRNA levels in the brain peaked during FOM stage. 


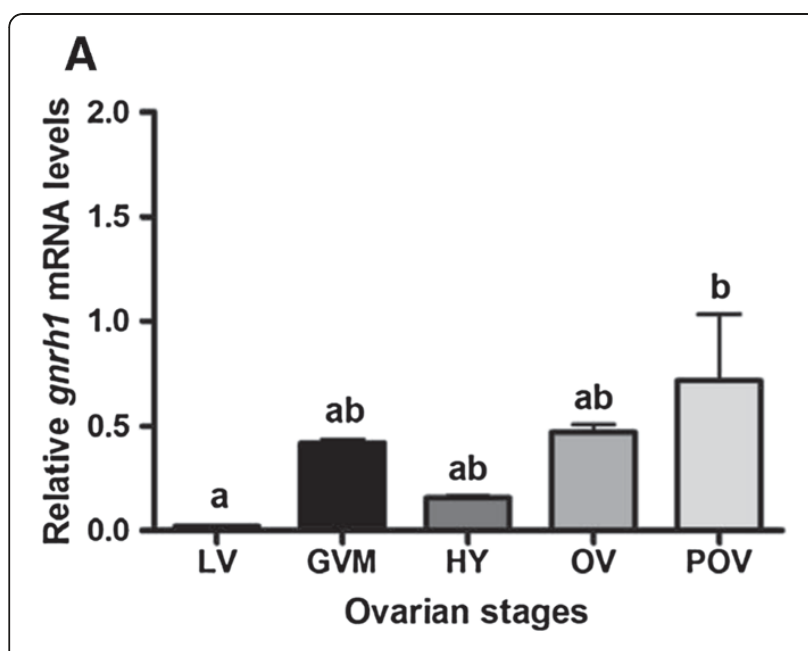

\section{B}

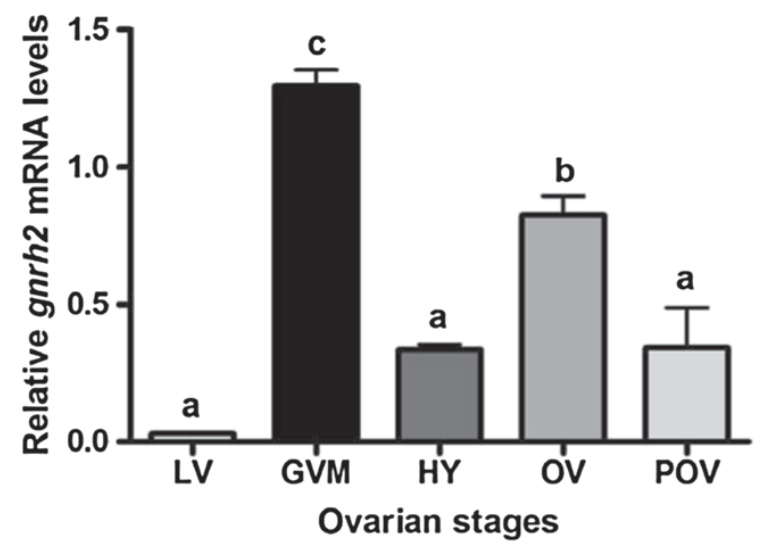

\section{C}

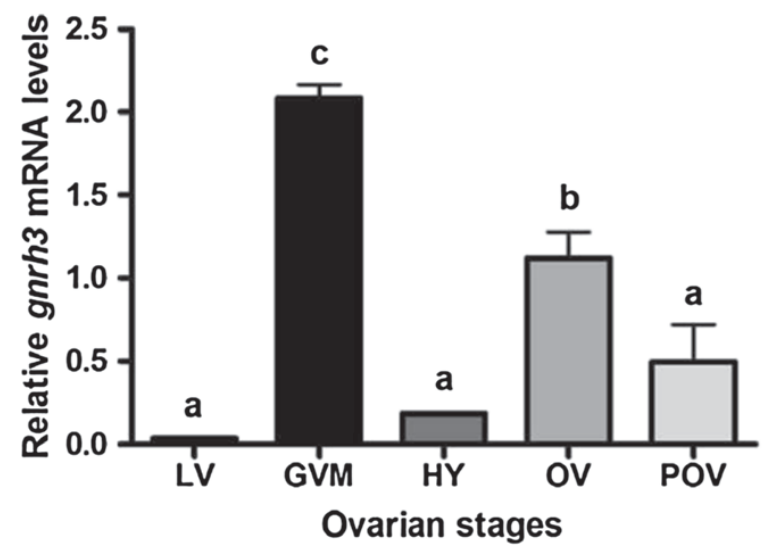

Figure 3 Changes in mRNA levels of gnrh1 (A), gnrh2 (B), and gnrh3 (C) in the brain of adult chub mackerel during different stages of spawning cycle. Each bar represents mean \pm SEM from 5-6 fish per ovarian stage (Refer Table 1). Different letters above the bars represent significant differences $(p<0.05)$ between stages. LV, late vitellogenesis; GVM, germinal vesicle migration; $\mathrm{HY}$, hydration; OV, ovulation; POV, post-ovulation.

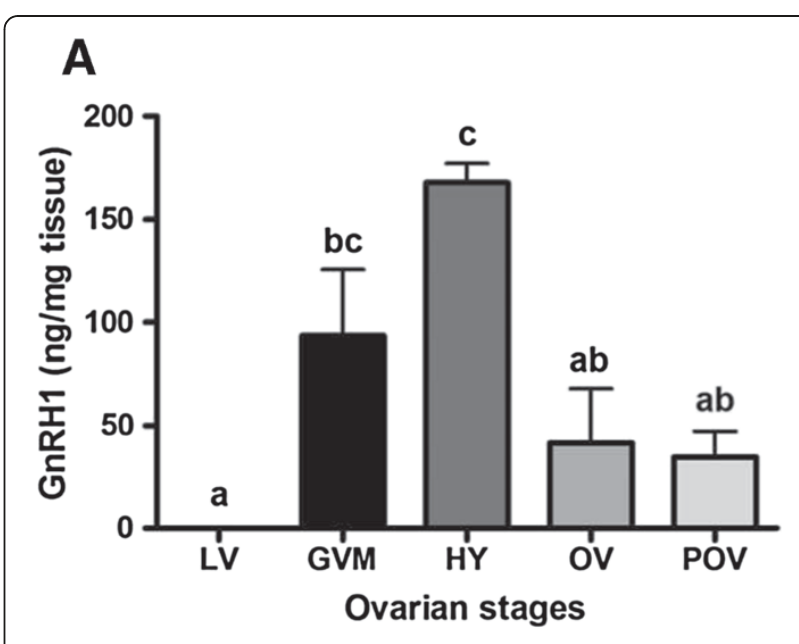

B
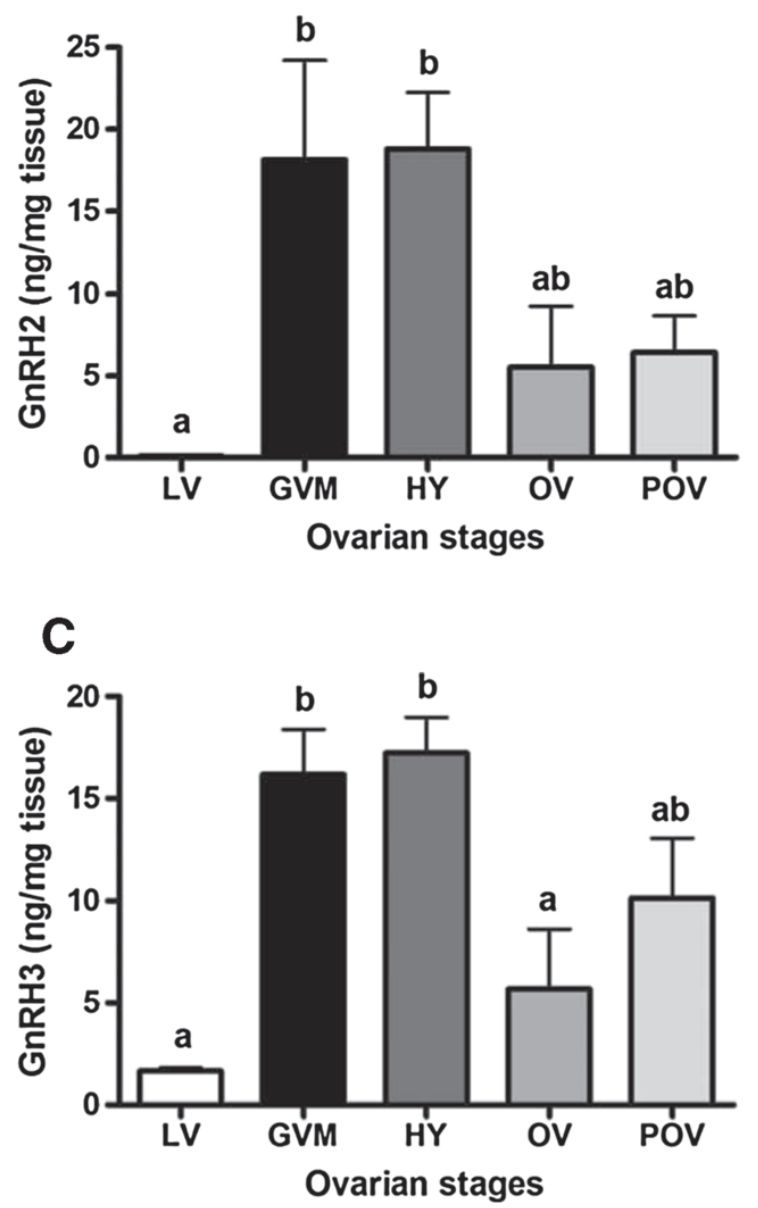

Figure 4 Changes in peptide levels of GnRH1 (A), GnRH2 (B), and $\mathrm{GnRH} 3(\mathrm{C})$ in the brain of adult chub mackerel during different stages of spawning cycle. Each bar represents mean \pm SEM from 4-6 fish per ovarian stage (Refer Table 1). Different letters above the bars represent significant differences $(p<0.05)$ between stages. LV, late vitellogenesis; GVM, germinal vesicle migration; $H Y$, hydration; OV, ovulation; POV, post-ovulation. 
However, it has been previously demonstrated that kiss1 levels did not show any fluctuation and kiss2 levels remained low during late vitellogenic and post-spawning periods in female chub mackerel [17]. These results suggest an ovarian stage dependent expression of kiss 1 and kiss 2 in the brain of chub mackerel. Similar observations on differential expression changes of kiss mRNAs in the brain at different reproductive stages of other teleosts were reported previously. Biran et al. [32] have found that in female zebrafish (Danio rerio), kiss1 mRNA levels in the brain gradually increased during the first 2-8 weeks of life to peak in fish with large mature vitellogenic follicles at 12 weeks. Subsequently, Kitahashi et al. [33] found both kiss1 and kiss 2 mRNA levels in the brain peaked 30 days after fertilization and remained high during puberty and adulthood. In grass pufferfish (Takifugu niphobles), expressing only kiss2, mRNA levels peaked in the brain and pituitary of adult mature and spawning females [34]. Similarly, in the brain of mature female striped bass (Morone saxatilis), both kiss 1 and kiss 2 mRNAs, including levels of their receptors gpr54-1 and gpr54-2, were found to be significantly increased in comparison to juvenile and prepubertal fish [35]. In female Senegalese sole (Solea senegalensis), Mechaly et al. [36] found highest kiss 2 mRNA expression in the forebrain and midbrain either before or during the spawning season. However, in Atlantic cod (Gadus morhua), kiss 2 mRNA expression in the brain was elevated in the vitellogenic females [37]. Based on these results, we hypothesize that increased kiss mRNA levels in the brain are likely involved in the regulation of FOM and ovulation in chub mackerel. Future studies on the investigation of kiss expression in the brain of naturally spawning female chub mackerel will help to clarify the proposed hypothesis.

Recent studies suggest that the expression of kisspeptin receptor appears to have a more critical role in regulating the reproductive processes than its ligand [38]. In sheep, administration of kisspeptin decapeptides (Kiss110) was shown to regulate expression of kisspeptin receptors in the brain [39]. Similarly, in a prepubertal yellowtail kingfish (Seriola lalandi), administration of Kiss2-10 showed a significant dose-dependent response in the relative mRNA expression of kisspeptin receptor (Kiss2r) [38]. Interestingly, in zebrafish, habenula kiss1 neurons were shown to coexpress kisspeptin receptor (kissr1) [33,40]. Further, administration of Kiss1-10 was shown to decrease habenula kiss1 mRNA expression, suggesting autocrine regulation of the kiss1 gene in the zebrafish [40]. In light of the above, we have recently isolated two isoforms of kisspeptin receptors from the brain of chub mackerel (Ohga et al., unpublished observations). Future analyses on the expression changes of kisspeptin receptors at different reproductive stages and ligand-receptor binding affinity will help to further clarify the role of kisspeptin system in the control of reproductive processes in chub mackerel. Recently, for the first time in fish, Beck et al. [41] revealed that exogenous administration of kisspeptin peptides has potential to accelerate gonadal development in the basses of the family Moronidae, and their hybrid. In line with the above report, functional studies of the effects of kisspeptin peptides on inducing gonadal growth and maturation in chub mackerel merits investigation.

Chub mackerel show asynchronous type of ovarian development, containing two or three clutches of vitellogenic oocytes of different diameters [42]. During spawning season, only a small percentage of first clutch late vitellogenic oocytes undergo FOM, hydration, ovulation, and spawning with successive progression of mid and early vitellogenic oocytes [16,43]. Interestingly, kiss 1 but not kiss 2 expression in the brain was found to increase during ovulatory and post-ovulatory periods, when the second clutch of vitellogenic oocytes is likely to undergo FOM on the following day (See Additional file 2: Figure S2). Our previous study [17] showed that during late vitellogenic and post-spawning periods, kiss 2 but not kiss1 expression in the brain decreased. The post-spawning period analyzed in our previous study [17] corresponds to termination of spawning season (August) and ovaries contain mainly atretic oocytes with degenerated late-vitellogenetic oocytes. In contrast, the post-ovulatory period analyzed in the present study corresponds to spawning season (April-June) and ovaries contain post-ovulatory follicles with two or three clutches of vitellogenic oocytes. Moreover, it is likely that these fish undergo repetitive spawning activity before termination of spawning season. These results suggest differential expression changes of kiss 1 and kiss 2 in the brain in response to unknown factors. The gonadal sex steroids have been demonstrated to act in the regulation of kisspeptin expression in the brain of mammals and teleosts $[44,45]$. For instance, among teleost fishes expressing two kiss forms (kiss1 and kiss2), ovarian estrogen has been shown to regulate region specific kiss expression in the brain. In the brain of medaka (Oryzias latipes), only kiss 1 neurons in the nucleus ventral tuberis (NVT) have shown to be up-regulated by ovarian estrogen $[46,47]$. However, in the brain of goldfish (Carassius auratus), only kiss 2 neurons in the preoptic area were shown to be up-regulated by ovarian estrogen [48]. Interestingly, in the prepubertal zebrafish, estradiol treatment was shown to enhance expression of both kiss 1 and kiss 2 [49]. Future studies on the localization of kiss expression in the brain and role of sex steroids on the regulation of kiss expression will help to further define the significance of differential expression changes of kiss 1 and kiss 2 in the brain of chub mackerel.

Presently, for chub mackerel there is no anatomical evidence to show that kisspeptin system is directly or 
indirectly involved in the regulation of GnRH neurons. For the first time, Parhar et al. [7] demonstrated coexpression of kisspeptin receptor in GnRH1, GnRH2, and GnRH3 neurons in Nile tilapia (Oreochromis niloticus). Subsequently, Nocillado et al. [50] found a positive correlation in the brain expression pattern of kisspeptin receptor and GnRH in female grey mullet (Mugil cephalus). In zebrafish, kisspeptin immunoreactive axonal fibers were shown to interact with hypophysiotropic GnRH3 neuronal systems [51]. Also, in the brain of female red seabream, expression changes of kiss2 mRNA were shown to correlate with number of GnRH1immunoreactive neurons [52]. Recently, in striped bass, kisspeptin receptor was colocalized in GnRH1 neurons, indicating direct influence of kisspeptin on regulation of GnRH1 neuronal system [35]. In the present study, we found that an increase in kiss1 and kiss2 mRNA levels coincided with an increase in gnrh2 and gnrh3 levels in the brain, including the peptide levels of all three GnRH forms during FOM. These findings, including the data of other studies, suggest that the role of kisspeptins in the regulation of GnRH neuronal system is likely conserved in the chub mackerel and merits future investigation on the colocalization of kisspeptin and $\mathrm{GnRH}$ system.

In several teleosts, either mRNA or peptide levels of the hypophysiotropic GnRH form, i.e., GnRH1 in teleosts expressing three GnRH forms, and mainly GnRH3 in the case of those expressing two forms, have been shown to fluctuate significantly during ovarian maturation or spawning season $[10,53]$. However, in the brain of gilthead seabream expressing three GnRH forms and showing asynchronous type of ovarian development as that of chub mackerel, elevation in the levels of all three GnRH mRNAs and plasma LH were found $8 \mathrm{~h}$ before spawning, when the germinal vesicle was located next to the micropyle of the oocyte [21]. This is in agreement with the findings of present study showing elevations in the levels of gnrh 2 and gnrh 3 mRNAs, including the peptide levels of GnRH1, GnRH2, GnRH3 forms in the brain during FOM stage, germinal vesicle migration (710h before spawning). In the chub mackerel, we did not find any significant rise in gnrh1 mRNA levels except during post-ovulatory period. However, it is interesting to note that this increase also coincided with an increase in the mRNA levels of pituitary gonadotropin subunits $(g p \alpha, f s h \beta, \operatorname{lh} \beta)$ analyzed in the same fish samples [15]. These results suggest that the stimulatory signal of gnrh1 contributing to increased pituitary $\operatorname{lh} \beta$ levels resulting in FOM, would have initiated $14-17 \mathrm{~h}$ before spawning in the chub mackerel. Since GnRH1 peptide levels were many-fold higher in the brain and pituitary of female chub mackerel during the FOM and ovulation stages, we propose GnRH1 form as the predominant regulator of maturation and spawning in chub mackerel. This is further supported by our previous data showing a dominant role of $\mathrm{GnRH} 1$ form in the regulation of vitellogenesis in chub mackerel [20].

\section{Conclusions}

The present study revealed significant fluctuations in the levels of two kiss mRNAs in the brain during the FOM and ovulatory periods. Further, levels of all three gnrh mRNAs and their peptides in the brain were found to fluctuate during FOM and ovulatory periods. These results indicate increased expression of multiple Kiss and GnRH forms in the brain and suggest their possible involvement in the regulation of FOM and ovulation in captive female chub mackerel. Future studies on the expression of kiss and gnrh mRNAs and changes in their peptide levels in the brain of naturally spawning female chub mackerel will be important to understanding their role in the reproductive dysfunction of captive fish.

\section{Additional files}

\begin{abstract}
Additional file 1: Figure S1. Changes in peptide levels of $\mathrm{GnRH} 1(\mathrm{~A})$, $\mathrm{GnRH} 2(\mathrm{~B})$, and $\mathrm{GnRH} 3(\mathrm{C})$ in the pituitary of adult chub mackerel during different stages of spawning cycle. Each bar represents mean \pm SEM from 4-6 fish per ovarian stage (Refer Table 1). Different letters above the bars represent significant differences $(p<0.05)$ between stages. LV, late vitellogenesis; GVM, germinal vesicle migration; $\mathrm{HY}$, hydration; OV, ovulation; POV, post-ovulation.

Additional file 2: Figure S2. Summarized figure showing expression changes of kiss1 (red line), kiss2 (blue line), gnrh1 (pink line), gnrh2 (green line), gnrh3 (purple line) mRNAs in the brain; GnRH1 (pink break line), $\mathrm{GnRH} 2$ (green break line), GnRH3 (purple break line) peptides in the brain and pituitary; gpa (brown line), fsh $\beta$ (yellow orange line), Ih $\beta$ (orange line) mRNAs (reported previously by Nyuji et al. [15]) in the pituitary of chub mackerel (Scomber japonicus) at different ovarian stages analyzed in the present study.
\end{abstract}

\section{Competing interests}

The authors declare that they have no competing interests.

\section{Authors' contributions}

SS and MM was responsible for the experimental design. SS was the principal writer of the manuscript and contributed to the mRNA expression analysis, data analysis, and interpretation of the results. HK, MY, and $\mathrm{HO}$ assisted in fish and tissue sampling. MA was responsible for $\mathrm{GnRH}$ peptide analyses. AY, AS, and MM contributed to the data interpretation and supervised this work. All authors read and approved the final manuscript.

\section{Acknowledgments}

We thank Mr. Akira Tabuchi of the School of Marine Biosciences, Kitasato University, for his kind help with the GnRH peptides measurement. This research was funded by a subproject on studies on the prediction and application of fish species alternation (SUPRFISH) financed by the Agriculture, Forestry and Fisheries Research Council (AFFRC) of Japan, as part of the Population Outbreak of Marine Life (POMAL) Project and a grant for scientific research (23658163) from the Ministry of Education, Culture, Sports, Science and Technology (MEXT) to MM. The first author SS is supported by the Japan Society for the Promotion of Science (JSPS) postdoctoral fellowship (P11406) for foreign researchers. 


\section{Author details}

'Laboratory of Marine Biology, Kyushu University, Fukuoka 812-8581, Japan.

${ }^{2}$ School of Marine Biosciences, Kitasato University, Sagamihara, Kanagawa

252-0373, Japan. ${ }^{3}$ Fisheries Research Agency, Kanazawa, Yokohama 236-8648, Japan.

Received: 31 May 2012 Accepted: 22 August 2012

Published: 27 August 2012

\section{References}

1. Nagahama Y, Yamashita M: Regulation of oocyte maturation in fish. Dev Growth Differ 2008, S1:S195-S219.

2. Yaron Z, Gur G, Melamed P, Rosenfeld H, Elizur A, Levavi-Sivan B: Regulation of fish gonadotropins. Int Rev Cytol 2003, 225:131-185.

3. Colledge $\mathrm{WH}$ : Kisspeptins and GnRH neuronal signalling. Trends Endocrinol Metab 2009, 20:115-121.

4. Hameed S, Jayasena CN, Dhillo WS: Kisspeptin and fertility. J Endocrinol 2011, 208:97-105.

5. Elizur A: The Kiss1/GPR54 system in fish. Peptides 2009, 30:164-170.

6. Tena-Sempere M, Felip A, Gómez A, Zanuy S, Carillo M: Comparative insights of the kisspeptin/kisspeptin receptor system: lessons from non-mammalian vertebrates. Gen Comp Endocrinol 2012, 175:234-243.

7. Parhar IS, Ogawa S, Sakuma Y: Laser-captured single digoxigenin-labeled neurons of gonadotropin releasing hormone types reveal a novel $\mathrm{G}$ protein-coupled receptor (Gpr54) during maturation in cichlid fish. Endocrinology 2003, 145:3613-3618.

8. Parhar I, Ogawa S, Kitahashi T: RFamide peptides as mediators in environmental control of GnRH neurons. Prog Neurobiol 2012, 98:176-196.

9. Kah O, Lethimonier C, Somoza G, Guilgur LG, Vaillant C, Lareyre JJ: GnRH and $\mathrm{GnRH}$ receptors in metazoan: a historical, comparative, and evolutive perspective. Gen Comp Endocrinol 2007, 153:346-364.

10. Okubo K, Nagahama Y: Structural and functional evolution of gonadotropinreleasing hormone in vertebrates. Acta Physiol 2008, 193:3-15.

11. Zohar Y, Muñoz-Cueto JA, Elizur A, Kah O: Neuroendocrinology of reproduction in teleost fish. Gen Comp Endocrinol 2010, 165:438-455.

12. Mendiola D, Yamashita Y, Matsuyama M, Alvarez P, Tanaka M: Scomber japonicus, $\mathrm{H}$. is a better candidate species for juvenile production activities than Scomber scombrus. L. Aqua Res 2008, 39:1122-1127.

13. Shiraishi T, Ohta K, Yamaguchi A, Yoda M, Chuda H, Matsuyama M: Reproductive parameters of the chub mackerel Scomber japonicus estimated from human chorionic gonadotropin induced final oocyte maturation and ovulation in captivity. Fish Sci 2005, 71:531-542.

14. Matsuyama M, Shiraishi T, Sundaray JK, Rahman MA, Ohta K, Yamaguchi A: Steroidogenesis in ovarian follicles of chub mackerel, Scomber japonicus. Zool Sci 2005, 22:101-110.

15. Nyuji M, Selvaraj S, Kitano H, Ohga H, Yoneda M, Shimizu A, Kaneko K, Yamaguchi A, Matsuyama M: Changes in the expression of pituitary gonadotropin subunits during reproductive cycle of multiple spawning female chub mackerel Scomber japonicus. Fish Physiol Biochem 2012, 38:883-897.

16. Shiraishi T, Ketkar SD, Kitano H, Nyuji M, Yamaguchi A, Matsuyama M: Time course of final oocyte maturation and ovulation in chub mackerel Scomber japonicus induced by hCG and GnRHa. Fish Sci 2008, 74:764-769.

17. Selvaraj S, Kitano H, Fujinaga Y, Ohga H, Yoneda M, Yamaguchi A, Shimizu A, Matsuyama M: Molecular characterization, tissue distribution, and mRNA expression profiles of two Kiss genes in the adult male and female chub mackerel (Scomber japonicus) during different gonadal stages. Gen Comp Endocrinol 2010, 169:28-38.

18. Fernald RD, White RB: Gonadotropin-releasing hormone genes: phylogeny, structure, and functions. Front Neuroendocrinol 1999, 20:224-240.

19. Selvaraj S, Kitano H, Fujinaga Y, Amano M, Takahashi A, Shimizu A, Yoneda M, Yamaguchi A, Matsuyama M: Immunological characterization and distribution of three GnRH forms in the brain and pituitary gland of chub mackerel (Scomber japonicus). Zool Sci 2009, 26:828-839.

20. Selvaraj S, Kitano H, Amano M, Nyuji M, Kaneko K, Yamaguchi A, Matsuyama M: Molecular characterization and expression profiles of three $\mathrm{GnRH}$ forms in the brain and pituitary of adult chub mackerel (Scomber japonicus) maintained in captivity. Aquaculture 2012, 356/35:200-210.

21. Gothilf $Y$, Meiri l, Elizur A, Zohar Y: Preovulatory changes in the levels of three gonadotropin-releasing hormone-encoding messenger ribonucleic acids (mRNAs), gonadotropin beta-subunit mRNAs, plasma gonadotropin, and steroids in the female gilthead seabream, Sparus aurata. Biol Reprod 1997, 57:1145-1154.

22. Vermeirssen ELM, Scott AP, Mylonas CC, Zohar Y: Gonadotrophin-releasing hormone agonist stimulates milt fluidity and plasma concentrations of $17,20 \beta$-dihydroxylated and $5 \beta$-reduced, 3a-hydroxylated $C_{21}$ steroids in male plaice (Pleuronectes platessa). Gen Comp Endocrinol 1998, 112:163-177.

23. Scott AP, Witthames PR, Vermeirssen ELM, Carolsfeld J: Prolonged-release gonadotropin-releasing hormone analogue implants enhance oocyte final maturation and ovulation, and increase plasma concentrations of sulphated C21 steroids in North Sea plaice. J Fish Biol 1999, 55:316-328.

24. Larionov A, Krause A, Miller W: A standard curve based method for relative real time PCR data processing. BMC Bioinformatics 2005, 62:1-16.

25. Bustin S, Benes V, Garson J, Hellemans J, Huggett J, Kubista M, Mueller R, Nolan T, Pfaffl M, Shipley G, Vandesompele J, Wittwer C: The MIQE guidelines: minimal information for publication of quantitative real-time PCR experiments. Clin Chem 2009, 55:611-622.

26. Okuzawa K, Amano M, Kobayashi M, Aida K, Hanyu I, Hasegawa Y, Miyamoto K: Differences in salmon GnRH and chicken GnRH-II contents in discrete brain areas of male and female rainbow trout according to age and stage of maturity. Gen Comp Endocrinol 1990, 80:116-126.

27. Pham KX, Amano M, Amiya N, Kurita Y, Yamamori K: Distribution of three GnRHs in the brain and pituitary of the wild Japanese flounder Paralichthys olivaceus. Fish Sci 2006, 72:89-94.

28. Yamada H, Amano M, Okuzawa K, Chiba H, Iwata M: Maturational changes in brain contents of salmon $\mathrm{GnRH}$ in rainbow trout as measured by a newly developed time-resolved fluoroimmunoassay. Gen Comp Endocrinol 2002, 126:136-143.

29. Amano M, Yamanome T, Yamada H, Okuzawa K, Yamamori K: Effects of photoperiod on gonadotropin-releasing hormone levels in the brain and pituitary of underyearling male barfin flounder. Fish Sci 2004, 70:812-818.

30. Shiraishi T, Ketkar SD, Katoh Y, Nyuji M, Yamaguchi A, Matsuyama M: Spawning frequency of the Tsushima current subpopulation of chub mackerel Scomber japonicus off Kyushu, Japan. Fish Sci 2009, 75:649-655.

31. Nyuji M, Shiraishi T, Selvaraj S, In W, Kitano H, Yamaguchi A, Okamoto K, Onoue S, Shimizu A, Matsuyama M: Immunoreactive changes in pituitary FSH and LH cells during seasonal reproductive and spawning cycles of female chub mackerel Scomber japonicus. Fish Sci 2011, 77:731-739.

32. Biran J, Ben-Dor S, Levavi-Sivan B: Molecular identification and functional characterization of the kisspeptin/kisspeptin receptor system in lower vertebrates. Biol Reprod 2008, 79:776-786.

33. Kitahashi T, Ogawa S, Parhar IS: Cloning and expression of kiss 2 in the zebrafish and medaka. Endocrinology 2009, 150:821-831.

34. Md S, Motohashi $\mathrm{E}$, Doi $H$, Ando H: Elevation of Kiss2 and its receptor gene expression in the brain and pituitary of grass puffer during the spawning season. Gen Comp Endocrinol 2010, 169:48-57.

35. Zmora N, Stubblefield J, Zulperi Z, Biran J, Levavi-Sivan B, Muñoz-Cueto JA Zohar Y: Differential and gonad stage-dependent roles of kisspeptin1 and kisspeptin2 in reproduction in the modern teleosts. Morone Species. Biol Reprod 2012, 86:177.

36. Mechaly AS, Viñas J, Piferrer F: Sex-specific changes in the expression of kisspeptin, kisspeptin receptor, gonadotropins and gonadotropin receptors in the Senegalese sole (Solea senegalensis) during a full reproductive cycle. Comp Biochem Physiol Part A 2012, 162:364-371.

37. Cowan M, Davie A, Migaud H: Photoperiod effects on the expression of kisspeptin and gonadotropin genes in Atlantic cod, Gadus morhua, during first maturation. Comp Biochem Physiol Part A 2012, 163:82-94.

38. Nocillado JN, Biran J, Lee YY, Levavi-Sivan B, Mechaly AS, Zohar Y, Elizur A: The Kiss2 receptor (Kiss2r) gene in southern bluefin tuna, Thunnus maccoyii and in yellowtail kingfish, Seriola lalandi - functional analysis and isolation of transcript variants. Mol Cell Endocrinol, 362:211-220.

39. Li Q, Roa A, Clarke IJ, Smith JT: Seasonal variation in the gonadotropinreleasing hormone response to kisspeptin in sheep: possible kisspeptin regulation of the kisspeptin receptor. Neuroendocrinology, in press.

40. Ogawa S, Ng KW, Ramadasan PN, Nathan FM, Parhar IS: Habenular Kiss1 neurons modulate the serotonergic system in the brain of zebrafish. Endocrinology 2012, 153:2398-2407.

41. Beck BH, Fuller SA, Peatman E, McEntire ME, Darwish A, Freeman DW: Chronic exogenous kisspeptin administration accelerates gonadal development in basses of the genus Morone. Comp Biochem Physiol Part A 2012, 162:265-273. 
42. Murua H, Saborido-Rey F: Female reproductive strategies of marine fish species of the North Atlantic. J NW Atl Fish Sci 2003, 33:23-31.

43. Yamada T, Aoki I, Mitani I: Spawning time, spawning frequency and fecundity of Japanese chub mackerel, Scomber japonicus in the waters around the Izu islands, Japan. Fish Res 1998, 38:83-89.

44. Garcia-Galiano D, Pinilla L, Tena-Sempere M: Sex steroids and the control of the kiss 1 system: developmental roles and major regulatory actions. J Neuroendocrinol 2012, 24:22-34.

45. Kanda S, Oka Y: Evolutionary insights into the steroid sensitive kiss1 and kiss2 neurons in the vertebrate brain. Front Endocrin 2012, 3:28.

46. Kanda S, Akazome Y, Matsunaga T, Yamamoto N, Yamada S, Tsukamura $\mathrm{H}$, Maeda K, Oka Y: Identification of KiSS-1 product kisspeptin and steroidsensitive sexually dimorphic kisspeptin neurons in medaka (Oryzias latipes). Endocrinology 2008, 149:2467-2476.

47. Mitani Y, Kanda S, Akazome Y, Zempo B, Oka Y: Hypothalamic Kiss1 but not Kiss2 neurons are involved in estrogen feedback in medaka (Oryzias latipes). Endocrinology 2010, 151:1751-1759.

48. Kanda S, Karigo T, Oka Y: Steroid sensitive kiss2 neurones in the goldfish: evolutionary insights into the duplicate kisspeptin gene-expressing neurones. J Neuroendocrinol 2012, 24:897-906.

49. Biran J, Palevitch O, Ben-Dor S, Levavi-Sivan B: Neurokinin Bs and neurokinin $B$ receptors in zebrafish-potential role in controlling fish reproduction. PNAS 2012, 109:10269-10274.

50. Nocillado JN, Levavi-Sivan B, Carrick F, Elizur A: Temporal expression of G-protein-coupled receptor 54 (GPR54), gonadotropin-releasing hormones $(\mathrm{GnRH})$, and dopamine receptor D2 (drd2) in pubertal female grey mullet, Mugil cephalus. Gen Comp Endocrinol 2007, 150:278-287.

51. Servili A, Page YL, Leprince J, Caraty A, Escobar S, Parhar IS, Seong JY, Vaudry H, Kah O: Organization of two independent kisspeptin systems derived from evolutionary-ancient kiss genes in the brain of zebrafish. Endocrinology 2011, 152:1527-1540.

52. Shimizu Y, Tomikawa J, Hirano K, Nanikawa Y, Akazome Y, Kanda S, Kazeto Y, Okuzawa K, Uenoyama Y, Ohkura S, Tsukamura H, Maeda KI, Gen K, Oka Y, Yamamoto N: Central distribution of kiss2 neurons and peri-pubertal changes in their expression in the brain of male and female red seabream Pagrus major. Gen Comp Endocrinol 2012, 175:432-442.

53. Amano M: Reproductive biology of salmoniform and pleuronectiform fishes with special reference to gonadotropin-releasing hormone (GnRH). Aqua-Biosci Monogr 2010, 3:39-72.

doi:10.1186/1477-7827-10-64

Cite this article as: Selvaraj et al.: Increased expression of kisspeptin and $\mathrm{GnRH}$ forms in the brain of scombroid fish during final ovarian maturation and ovulation. Reproductive Biology and Endocrinology 2012 $10: 64$.

\section{Submit your next manuscript to BioMed Central and take full advantage of:}

- Convenient online submission

- Thorough peer review

- No space constraints or color figure charges

- Immediate publication on acceptance

- Inclusion in PubMed, CAS, Scopus and Google Scholar

- Research which is freely available for redistribution 